\title{
Intercultural Comparison of E-Learning Behaviors of Chinese vs. American Students
}

\section{Author: Shihua Chen Brazill}

The final publication is available at Springer via http://dx.doi.org/10.1007/978-981-13-9895-7 26.

Shihua Brazill, (2019). "Intercultural Comparison of E-Learning Behaviors of Chinese vs.

American Students." In: Cheung S., Jiao J., Lee LK., Zhang X., Li K., Zhan Z. (eds) Technology in Education: Pedagogical Innovations. Communications in Computer and Information Science, vol 1048 (pp. 288-299). Springer.

Made available through Montana State University's ScholarWorks

scholarworks. montana.edu 


\title{
Intercultural Comparison of E-learning Behaviors of Chinese vs. American Students
}

\author{
Shihua Chen Brazill \\ Department of Education, Montana State University. \\ Bozeman, Montana, USA \\ shihuabrazill@montana.edu
}

Acknowledgment: I am very thankful for the generous support from the Department of Education, the College of EHHD, and the Graduate School from Montana State University for the travel funding to present at the $4^{\text {th }}$ International Conference on Technology in Education.

\begin{abstract}
This paper focuses on E-learning and intercultural studies of Chinese and American students. The paper is divided into six sections including Introduction, Intercultural Comparisons of Chinese and American Students, Elearning, Instructional Design for E-Learning, Cultural Theory for E-learning, and Conclusion. As a practical result, this paper is useful to researchers and practitioners who wish to know and understand cultural differences and ELearning behaviors of Chinese and American students. This knowledge could enhance online teacher-student interactions, improve E-learning outcomes, and identify salient cultural communication differences.
\end{abstract}

Keywords: Chinese and American Students, E-learning, Instructional Design for E-Learning, Cultural Theory for E-learning

\section{Introduction}

This section begins by defining key terms for the study, including E-learning and intercultural studies. According to Sangra, Vlachopoulos, and Cabrera (2012), an inclusive definition of E-learning includes four categories: technology-driven, delivery-system-oriented, communication-oriented, and educational-paradigmoriented. The authors defined E-learning as "representing the educational model applied, that is based on the use of electronic media and devices as tools for improving access to training, communication and interaction and that facilitates the adoption of new ways of understanding and developing learning" (p.152). Intercultural studies are about how students from distinct social groups or cultures exchange information or interact in certain ways (Triandis, 1989). Culturally responsive teaching is defined as "using the cultural characteristics, experiences, and perspectives of ethnically diverse students as conduits for teaching them more effectively" and can improve learners' experience in today's multicultural education classroom (Gay, 2002, p.106).

According to Wang (2007), cultural identity and communication styles strongly influence students' E-learning behaviors, engagements, and interactions. Cultural identity is the primary culture in which an individual grew up (Wang, 2007, p.4). 
Through my Chinese American background and experience teaching both American and Chinese students in E-learning classrooms, I have observed that most American students are bold in class; they ask questions and are comfortable with online discussion boards. In contrast, most Chinese students are more reserved and nervous with online discussions; they often find it difficult to express their opinions in writing because they are used to communicating face-to-face with peers and instructors, but in the Chinese educational system they are discouraged from stating their own ideas in writing.

\section{Intercultural Comparisons of Chinese and American Students}

This review paper compares Chinese and American students' E-learning behaviors for instructors to improve their E-learning curriculum development. To understand Elearning and cultural effects on Chinese and American learners, it is imperative that we first understand good practices that affect learning in the general sense. There are seven good practices in undergraduate education and instruction:

1. Encourage contact between students and faculty;

2. Develop reciprocity and cooperation among students;

3. Encourage active learning;

4. Give prompt feedback;

5. Emphasize time on task;

6. Communicate high expectations; and

7. Respect diverse talents and ways of learning

(Chickering \& Gamson, 1987, pp.3-5).

The last practice, respect diverse talents and ways of learning, is evident in classroom environments and fosters good academic behavior. There are some evidence that Chinese and American students learn differently (Andrade, 2006; Bista \& Foster, 2011; Chen, Bennett, \& Maton, 2008; Wan, 1999). One approach to understanding how Chinese and American students might think and learn differently is based on the differences between Confucian (Eastern) and Socratic (Western) approaches.

As the primary educational models used by Eastern and Western cultures, a comparison of the Confucian and Socratic approaches may unpack the influence of culture on learning styles. Gorry (2011) describes how Chinese and American learning styles differ due to Socratic and Confucian approaches. Chinese students learn the Confucian approach in their schooling, which Gorry (2011) describes as "a didactic teacher-centered pedagogy with a greater emphasis on strategic and direct thinking" (p.4). In the Confucian approach, the instructor serves as a manager and an authority figure. Students tend to be surface-level processors, i.e. memorizing knowledge and material without questioning the sources.

However, the Socratic approach is based on "an experiential learner-centered pedagogy that values creativity and intellectual independence" (p.4). For the Socratic approach, the instructor is a facilitator and a midwife (p.6). Socrates's mother was a midwife, and he used this analogy as a model for education: "as a 'midwife of ideas', helping others to bring forth ideas, but not himself giving birth to ideas, in the same way that a midwife helps a woman to give birth without interfering too much in the birth process" (Vivilaki \& Johnson, 2008, pp.90-91). The Socratic approach is also 
associated with individualistic Western culture explained by Hofstede's cultural dimensions theory (Kang \& Chang, 2016). Students are encouraged to process at a deep level, with reflection that might be signified through practical applications of theory.

Kang \& Chang (2016) believe that social hierarchy and harmony are valued in the Confucian approach while personal freedom and individuality are valued in the Socratic approach. Therefore, instructors can help students from Confucian cultures study in Western E-learning environments by providing "collaborative team projects and eliminating competition" (Kang \& Chang, 2016, p.790).

Furthermore, Kang \& Chang (2016) explain that American students value freedom and individualism. For student learning behaviors this is like the idiom "you can lead a horse to water, but you can't make it drink." My personal learning and teaching experiences in the U.S. higher education have shown that if an American student fails to attend lectures, finish his or her assignments, or complete required readings, most instructors do not micro-manage the student; it is the student's individual responsibility. However, the teacher's cultural identity also plays a part in how the elearning environment is set up.

Spizzica (1997) describes the teaching and learning cultural differences within "Western" and "Eastern" education. For Eastern education, "teacher-centered education, students need to accept teacher's opinions without giving own critique and memorization is a key tool in learning (p.9)" and for Western education, "studentcentered education, critical analysis is a key tool in learning" (p.9). Chinese and American learning styles are examples of the broader contrast between Eastern and Western education. Western students' learning strategies starts with exploration while Chinese children learn through concrete examples (Wong, 2004). Wang (2012) \& Brazill (2016) assert that Chinese students tend to think circularly, while English speakers tend to think linearly (see Fig. 1).

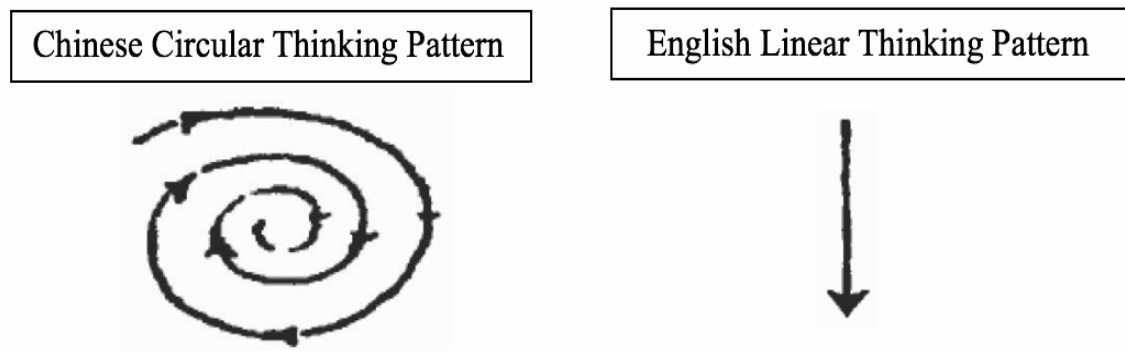

Fig. 1. Different thinking patterns (Source: "Causes of and Remedies for Chinglish in Chinese College Students' Writings," by P. Wang, and W. Wang, 2012, June 12, Open Journal of Modern Linguistics, 2(02), p.71. Copyright 2012 by SciRes.)

Clifford (2008) describes a scenario in which an Asian student studying in the West shared his point of view about classroom discussions. The student explained that in classes with professors, he never talked or asked any questions. He would wait for other students to ask questions for him. The other Western students would argue with professors, which made him uncomfortable. 
This perspective from an Asian student explains much about why Chinese students do not challenge or question their teachers and peers. Chinese students are often perceived as harmonious, cooperative, and respectful (Hwang, 1987). Kumaravadivelu (2003) elucidates a common stereotype about Chinese students, that they trust and obey authority - their teachers, readings, and other sources of knowledge conversations. This stereotype is evident as explained by cultural identity theory as the value, beliefs, thinking patterns, and behaviors that are shared and that characterizes as a group of people.

Chinese students must memorize material for the examination system in China, but they may not fully understand the concepts or be able to put them into practice; this is an example of rote learning (Kember, 2000). Sit (2013) observes that some researchers think Chinese students fall into the category of "silent learning", which can be traced to Confucian cultural influences that require students to respect hierarchical relationships. Chinese students are taught not to interrupt their teachers during class. Most Chinese students and teachers believe that wasting other students' class time by expressing independent opinions and concerns are considered inappropriate and selfish behavior, which also might cause teachers to "lose face" (Hu, 1944; Ho, 1976). Thus, Americans have the misconception that Chinese students do not ask questions (Kennedy, 2002). The underlying misconception and generalization that Americans hold about Chinese students is that they are passive learners (Kember, 2000).

However, this misconception is not quite true. Zeng (2006) claims that Chinese college students not only learn from their professors, but also interact with their professors after class to clarify any confusion in their learning material. These nonclassroom interactions have a positive effect on their career aspirations. Some Chinese students write down their questions during class and wait until after class to talk with their teachers. Chinese teachers are helpful, encouraging, and think highly of those students who ask questions after class. As Pratt, Kelly, and Wong (1999) point out, the harmonious interactions between Chinese teachers and students are not limited to a short-term relationship and academic learning but are part of the life-long positive influence that Chinese teachers have on their students as role models. In contrast, American students are encouraged to be critical and challenge their teachers in the classroom (Ladson, 1995). The effects of being critical and challenging teachers is evidence that American students are self-directed learners and they construct knowledge by challenging their teachers (Kang \& Chang, 2016, p.790).

Chinese students process and construct knowledge differently than American students through inquiry with their instructors. Cheng (2000) describes a well-known Chinese motto, Qin Xue Hao Wen, which means a good student should be diligent and always be ready to ask questions ("Xue" refers to "learn" and "wen" means "inquiry"). It stresses the importance of inquiry, so Chinese students do employ a deeper approach to learning that goes beyond memorization. Tu (2001) suggests that Chinese learners require clear instructions in an E-learning classroom discussion due to their cultural Identity in contrast to the open discussions that American students take for granted. According to a study by Yuan (2011), American students are expected to speak up in classroom discussions because being quiet is considered a marker for incompetence, lack of confidence, and unpreparedness. Furthermore, American 
students are taught to apply knowledge to hands-on projects. Therefore, it appears that cultural differences impact students' E-learning behaviors.

\section{$3 \quad$ E-Learning}

E-learning uses digital material on the Internet and computer-mediated instructional (CMI) systems as an environment for the exchange of information and interaction between learners and instructors (Bermejo, 2005). CMI is teaching using computers as tools to exchange texts, images, audios, and videos (Fitzgerald, Koury, \& Mitchem, 2008). E-learning is a kind of CMI, which can be synchronous, asynchronous, or realtime interaction through learning management systems (Colace, De Santo, \& Vento, 2003).

E-learning (synonyms of terms for E-learning are distance, online, hybrid, and blended learning/flipped classroom) is both a form and the process that occurs when consuming and interacting with $\mathrm{CMI}$ and new media. In contrast to traditional media (newspapers, magazines, books, television and other non-interactive media), new media is broadly defined as various kinds of digital communications (websites, online videos/audios/social platforms/communities, blogs, and other mediums that allow interactivity) that are possibly due to innovation in computer technology (Liu, Liao, \& Pratt, 2009).

\section{$4 \quad$ Instructional Design for E-Learning}

Instructional design methods are fundamental for enhancing E-learning experience. Swan (2002) argues that various methods can be used to significantly improve Elearning outcomes. These methods are clarity and consistency in course design, promoting feedback, active discussions, and interaction with course content, instructors, as well as peers. Hence the need for blogs, chat groups, and other forms of group and individual instructional interactions and contacts. Bowen (2017) emphasizes the backward design approach in E-learning, which begins with course outcomes and objectives, then assessment evidence, and then the planning. These three stages in the backward design model are classified as: identify desired results, determine acceptable assessment, and plan learning experiences and instruction to achieve the desired results. Granic \& Cukusic (2007) identify Universal Design within the context of E-Learning environment prompting individualization, ensuring usability, accessibility, and inclusive to diverse learners.

Keller's (1987) ARCS model of motivation is an instructional design model and theory that applies to both face-to-face and E-learning environments. The ARCS Model stands for attention (A), relevance (R), confidence (C), and satisfaction (S). It's a seminal model and it is the basis of many current studies. First and foremost, Elearning material must be interesting and able to keep students' attention. Second, Elearning material must be relatable to students' experiences and future career needs. Third, E-learning material must have clear objectives and build students' confidence. Fourth, E-learning material must have a reward process such as positive comments or feedback from instructors. Research indicates that Keller' ARCS model of motivation positively affects students' learning outcomes. Furthermore, Marzano \& Pickering 
(2010) provide insightful strategies (for example, using effective pacing, demonstrating intensity and enthusiasm, building positive teacher-student, and peer relationships connecting to students' lives, etc.) that engage students in the short-term and long-term which can apply in E-learning classrooms.

According to Garrison, Anderson, \& Archer (2001), the Inquiry-based Learning Model offers us specific guidelines when it comes to designing web-based courses. Like the ARCS model, it is a best practice for both face-to-face and E-learning. As shown in Fig. 2, the model emphasizes social presence, teaching presence, and cognitive presence. Social presence is defined as to project personal characteristics into the classroom by presenting to others as "real people." Teaching presence includes the design, presentation, assessment, facilitation of the teaching material, engagement and relationships with the students. Cognitive presence is especially important for web-based course design and is defined by the ability of students to construct meanings behind texts and to apply critical thinking skills in online courses.

Furthermore, The Inquiry-based Learning Model can be adapted to E-learning. It encourages students to ask good questions, and students and faculty to have frequent interactions. For example, online instructors can establish teaching presence by putting a face on video lectures with interactive quizzes rather than giving students separate and purely text-based materials. An inquiry-based learning framework could be used in E-learning in the following ways: setting clear expectations, making frequent course announcements, providing social forums, posting lectures, hosting teacher-led discussions, and encouraging student-led discussions.

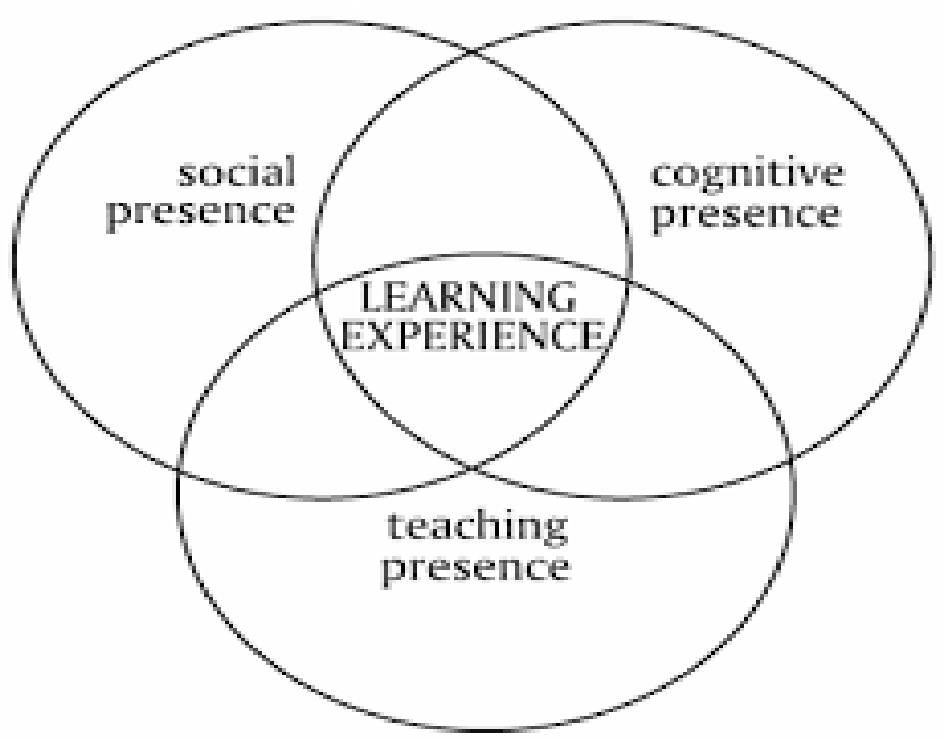

Fig. 2. Community of inquiry model (Source: "Critical inquiry in a text-based environment: Computer conferencing in higher education model.," by D. Garrison, W. Archer, \& R. Anderson, 1999, Spring, The Internet and Higher Education, 2(2-3), p. 88. Copyright 2000 by Elsevier Science Inc.) 
Additionally, Bloom's (1965) taxonomy of learning framework is a cognitive structural approach that works well in combination with the community of the inquiry model. Fig. 3 shows how Bloom's taxonomy of learning clearly defines learning objectives as a cognitive process that unfolds in discrete stages. This review will draw on Bloom's theory and define the levels of differences between Chinese and American students' E-learning behaviors.

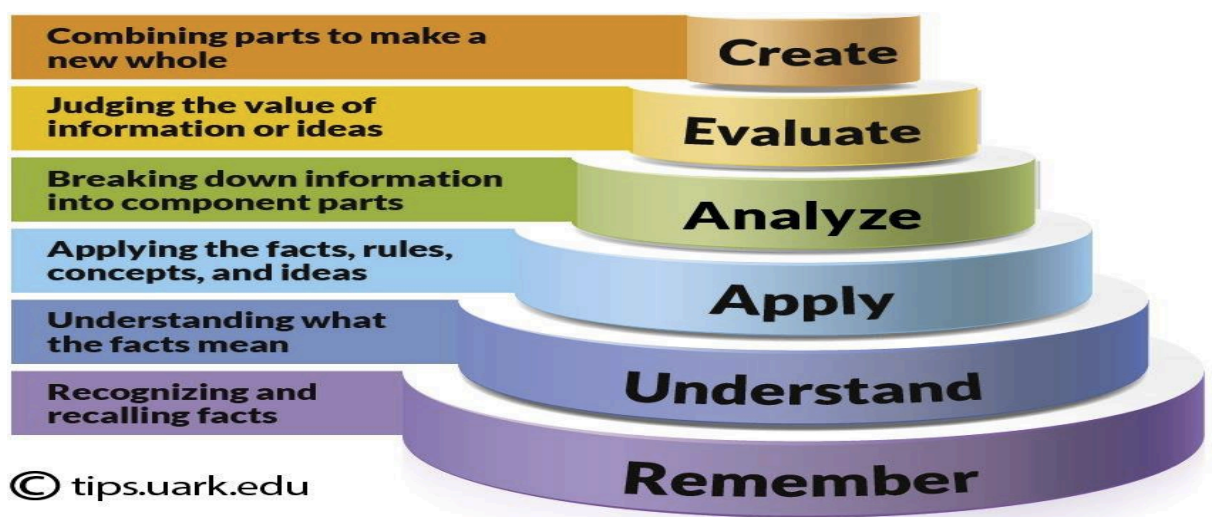

Fig. 3. Bloom's taxonomy of learning (Source: 'Using Bloom's Taxonomy to Write Effective Learning Objectives.," by J. Shabatu, 2018, May 19, Tips University of Arkansas, Retrieved March 11, 2019 from https://tips.uark.edu/using-bloomstaxonomy/. Copyright 2018 by University of Arkansas.)

Although many of these models were developed for face-to-face learning, the special features of E-learning make it suitable for the adaptation of these models. In order to maximize E-learning, instructional design should be culturally sensitive to students in the class. When focused on students from diverse cultures, E-learning is also an example of the global flow of information and culture (Ismail, 2001). Wang (2006) suggests culturally sensitive strategies for teaching students from different cultures by facilitating social communications among students through activities and encourage students to share their biographies, family stories, or other personal experience.

\section{Cultural Theory for E-learning}

It is imperative for this study that I understand cultural theory for E-learning design. Cultural diversity in E-learning is an increasingly popular topic because the US has become known as a melting pot and salad bowl with many incoming international students (many from China) from diverse cultures who lack E-learning experience and skills. Chinese and American students learn quite differently, and because these two nations are educational leaders it is especially important that we understand Elearning in an intercultural context and develop intercultural communication competency, which is the ability for one to communicate effectively and appropriately with people of other cultures. 
Keller's ARCS model of motivation (1987) described above is intended to apply to all cultures but does not explicitly incorporate cultural dimensions and values. To remedy this gap, Hofstede's Cultural Dimensions Theory (1984) can be applied to design courses for students from a variety of different cultures. It is a framework focusing on observable or measurable criteria such as:

- $\quad$ Power distance;

- $\quad$ Collectivism vs. Individualism;

- $\quad$ Femininity vs. Masculinity;

- Uncertainty vs. Avoidance;

- $\quad$ Long/short term orientation; and

- Indulgence vs. Restraint.

Over the years, many researchers have documented profound differences between Chinese (Eastern) and American (Western) culture. Hofstede's study of Cultural Dimensions has emerged as a popular and widely cited work that provides insights into the two cultural dimensions in ways that give course developers and teachers insights into E-learning behaviors and other practical aspects of communication.

We think of China and the United States as being very different in terms of language. This is true, but more importantly the two populations are profoundly different in cultural, social, and other ways that shape communication patterns and Elearning education practices.

There is also a great difference in the two cultures" "Long Term Orientation" scores. Hofstede's (1984) describes Americans as conservative, they believe the truth of American culture never changes, there are absolute moral values defining good and evil, and they look for quick results. Chinese, on the other hand, are very pragmatic and quickly adapt to changing times, and are willing to set long-term goals and endure a lot of pain (or "eat bitter"; chi ku) to reach them. This helps explain "Chinese Anxiety regarding Modernism" (Xie, 2008)", wherein "Modern" is equated with "Western". Thus, many Chinese young people desire to adopt Western values by living more in the moment and being more individualistic, especially while living in the US. Fig. 4 shows Hofstede Cultural Dimensions for China and the U.S. Americans are very individualistic whereas Chinese are very collectivist-i.e. Chinese people tend to define identity through group membership (Yeh \& Huang, 1996; Ardichvili, Maurer, Wentling, \& Stuedemann, 2006). 


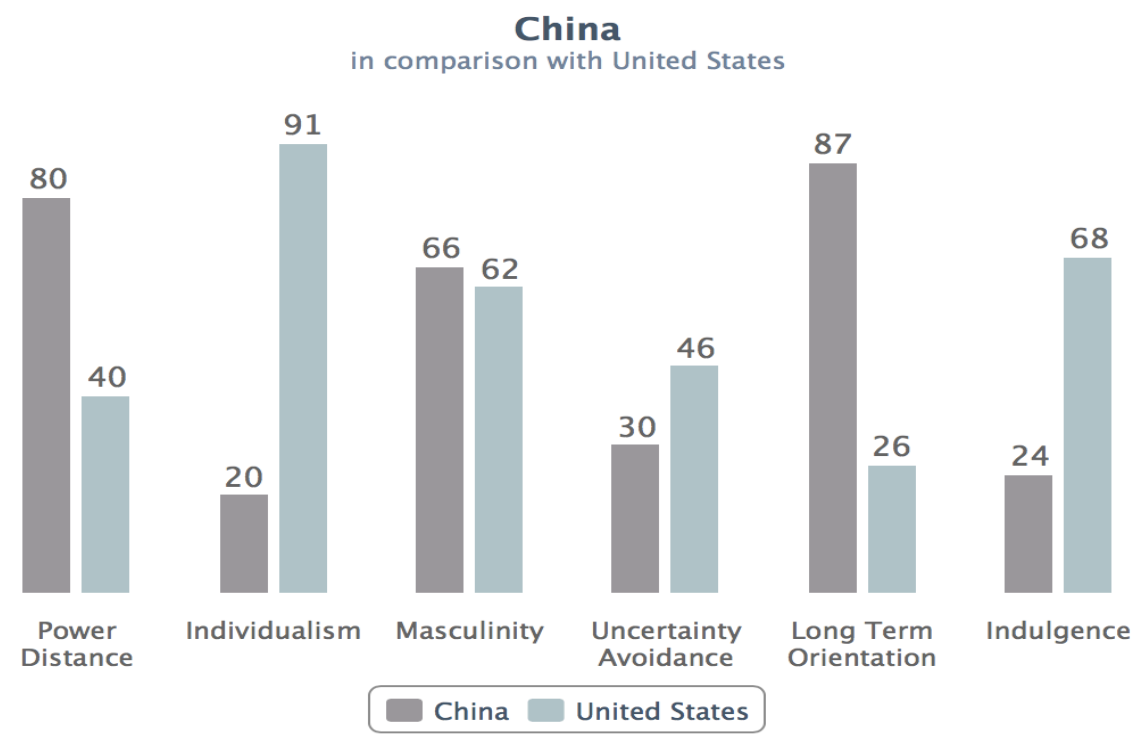

Fig. 4. Hofstede cultural dimensions (Source: "Hofstede Insights," by G. Hofstede, 2018, Country Comparison What about China, Retrieved November 11, 2018 from https://www.hofstede-insights.com/country-comparison/china,the-usa/. Copyright 2018 by Hofstede Insights.)

Likewise, Hall's (1976) cultural classification of high-context vs. low-context provides a cultural theoretical framework for E-learning. Hall's theory explains how culture drives learning behavior and thus requires personal instruction techniques. High-context cultures communicate in ways that are implicit and rely heavily on context. In contrast, low-context cultures rely on explicit verbal communication. America is known as a "low-context" culture, whereas Chinese culture is known as "high-context" and Chinese language is full of ambiguity. In high-context cultures, an understanding of unspoken rules of engagement and indirect implicit communication is required. In low-context cultures (e.g. Western cultures), a direct and explicit approach is the key for effective communication between independent individuals. This is especially important for E-learning instructional design and assignments. According to Tu (2001), students from low-context cultures will likely be fully engaged in discussion boards or essay questions because the low use of nonverbal elements, and that meanings are carried more by words than by nonverbal means. However, for students from high-context cultures to share their perspectives, assignments should include audio or visual content or be given through a social media platform because Chinese students rely more heavily than Western students on verbal and non-verbal cues from the instructors to share ideas. 


\section{Conclusion}

While researchers (Li, 1998; Rapaille, 2007; Culture Code, 2011; Yu, 2013; Brazill, 2019) have examined the differences between Chinese and American cultures, few studies have explored potential differences among Chinese and American students enrolled in E-Learning education. E-learning has become increasingly common for American university students, but little thought has been given to the role of cultural dimensions. It is vital to meet the needs of diverse students and to maximize learning outcomes in E-learning. The review paper addresses this knowledge-gap on how culture shapes E-learning behavior in online undergraduate education. It will provide guidance to universities and instructors on becoming more culturally sensitive to students' learning behavior. It will allow us to test many assumptions about intercultural communication, E-learning, computer-mediated communication and cultural identity theory. And, finally, it would improve students' learning outcomes in the online learning environment. 


\section{References}

Andrade, M. S. (2006). International students in English-speaking universities: Adjustment factors. Journal of Research in International education, 5(2), 131-154.

Ardichvili, A., Maurer, M., Li, W., Wentling, T., \& Stuedemann, R. (2006). Cultural influences on knowledge sharing through online communities of practice. Journal of Knowledge Management, 10(1), 94-107.

Bermejo, S. (2005). Cooperative electronic learning in virtual laboratories through forums. IEEE Transactions on Education, 48(1), 140-149.

Brazill, S. C. (2019). Factors that Predict ACT Science Scores from a Multicultural Perspective." Educational Research: Theory and Practice, 30(2), 1-16.

Brazill, S. C. (2016). Chinese to English translation: Identifying problems and providing solutions. http://digitalcommons.mtech.edu/grad $\mathrm{rsch} / 71$

Brazill, S. C. (2016). Analysis of Human vs. Machine Translation Accuracy, TRANSLATOLOGIA. http://www.translatologia.ukf.sk/2017/01/analysisof-human-versus-machine-translation-accuracy/

Bista, K., \& Foster, C. (2011). Issues of international student retention in American higher education. The International Journal of Research and Review, 7(2), 110.

Bowen, R. S. (2017). Understanding by Design. Vanderbilt University Center for Teaching. $\quad$ Retrieved March 11, 2019 from https://cft.vanderbilt.edu/understanding-by-design/.

Bloom, T. M. E. (1965). Bloom's taxonomy of educational objectives. Longman.

Chen, R. T. H., Bennett, S., \& Maton, K. (2008). The adaptation of Chinese international students to online flexible learning: Two case studies. Distance Education, 29(3), 307-323.

Cheng, X. (2000). Asian students' reticence revisited. System, 28(3), 435-446.

Chickering, A. W., \& Gamson, Z. F. (1987). Seven principles for good practice in undergraduate education. AAHE bulletin, 3, 7.

Clifford, V. (2008). Teaching international students (PPT presentation). Oxford Brookers University. Retrieved Nov 11, 2018 from https://www.sheffield.ac.uk/polopoly_fs/1.18985!/file/Teaching-InternationalStudents-Presentation.ppt.

Colace, F., De Santo, M., \& Vento, M. (2003, January). Evaluating on-line learning platforms: a case study. In System Sciences, 2003. Proceedings of the 36th Annual Hawaii International Conference on (pp. 9-pp). IEEE.

Cultural Code Leveraging the workplace to meet today's global challenges (2011). Cultural Code. Retrieved November 11, 2018, from https://www.steelcase.com/content/uploads/2014/03/360MagazineIssue65.pdf

Fitzgerald, G., Koury, K., \& Mitchem, K. (2008). Research on computer-mediated instruction for students with high incidence disabilities. Journal of Educational Computing Research, 38(2), 201-233.

Garrison, D. R., Anderson, T., \& Archer, W. (1999). Critical inquiry in a text-based environment: Computer conferencing in higher education model. The Internet and Higher Education, 2(2-3), 87-105. 
Gay, G. (2002). Preparing for culturally responsive teaching. Journal of teacher education, 53(2), 106-116.

Gold, T., Guthrie, D., \& Wank, D. (Eds.). (2002). Social connections in China: Institutions, culture, and the changing nature of guanxi. New York, NY: Cambridge University Press.

Gorry, J. (2011). Cultures of learning and learning culture: Socratic and Confucian approaches to teaching and learning. Learning and Teaching, 4(3), 4-18.

Granić, A., \& Ćukušić, M. (2007, July). Universal Design within the Context of eLearning. In International Conference on Universal Access in HumanComputer Interaction (pp. 617-626). Springer, Berlin, Heidelberg.

Hofstede, G. (1984). Cultural dimensions in management and planning. Asia Pacific journal of management, 1(2), 81-99.

Hofstede, G. (2018). Country comparison. Retrieved Nov 11, 2018 from https://www.hofstede-insights.com/country-comparison/china,the-usa/

Ho, D. Y. F. (1976). On the concept of face. American journal of sociology, 81(4), $867-884$

Hu, H. C. (1944). The Chinese concepts of "face". American anthropologist, 46(1), 45-64.

Hwang, K. K. (1987). Face and favor: The Chinese power game. American journal of Sociology, 92(4), 944-974.

Ismail, J. (2001). The design of an e-learning system: Beyond the hype. The internet and higher education, 4(3-4), 329-336.

Kang, H., \& Chang, B. (2016). Examining Culture's Impact on the Learning Behaviors of International Students from Confucius Culture Studying in Western Online Learning Context. Journal of International Students, 6(3), 779-797.

Keller, J. M. (1987). Development and use of the ARCS model of instructional design. Journal of instructional development, 10(3), 2-10.

Kennedy, P. (2002). Learning cultures and learning styles: Myth-understandings about adult (Hong Kong) Chinese learners. International journal of lifelong education, 21(5), 430-445.

Kember, D. (2000). Misconceptions about the learning approaches, motivation and study practices of Asian students. Higher education, 40(1), 99-121.

Kumaravadivelu, B. (2003). A postmethod perspective on English language teaching. World Englishes, 22(4), 539-550.

Lang, Y., Wang, L., Xie, C., \& Chen, W. (2014). An exploratory study on the use of I love you in the American context. International Journal of Society, Culture \& Language, 1-19.

Ladson-Billings, G. (1995). But that's just good teaching! The case for culturally relevant pedagogy. Theory into practice, 34(3), 159-165.

Li, Y. (1998). Cultural factors in translation. Perspectives: Studies in Translatology, 6(2), 175-182.

Liu, S. H., Liao, H. L., \& Pratt, J. A. (2009). Impact of media richness and flow on elearning technology acceptance. Computers \& Education, 52(3), 599-607.

Marzano, R. J., \& Pickering, D. J. (2010). The highly engaged classroom. Solution Tree Press. 
Pratt, D. D., Kelly, M. \& Wong, W. S. S. (1999). Chinese conceptions of 'effective teaching' in Hong Kong: Towards culturally sensitive evaluation of teaching. International Journal of Lifelong Education, 18(4), 241-258.

Rapaille, C. (2007). The culture code: An ingenious way to understand why people around the world live and buy as they do. New York: Crown Pub.

Pham, M. T. (2010). Meeting students' needs and expectations in a culturally diverse e-learning environment: a case study. The University of Texas at Austin.

Picciano, A. G. (2002). Beyond student perceptions: Issues of interaction, presence, and performance in an online course. Journal of Asynchronous learning networks, 6(1), 21-40.

Sangrà, A., Vlachopoulos, D., \& Cabrera, N. (2012). Building an inclusive definition of e-learning: An approach to the conceptual framework. The International Review of Research in Open and Distributed Learning, 13(2), 145-159.

Shabatu, J. (2018). Using Bloom's Taxonomy to Write Effective Learning Objectives. Retrieved Nov 11, 2018 from https://tips.uark.edu/using-blooms-taxonomy/

Spizzica, M. (1997). Cultural differences within "Western" and "Eastern" education. Academic communication across disciplines and cultures, 2, 24857.

Sit, H. H. W. (2013). Characteristics of Chinese students' learning styles. International Proceedings of Economics Development and Research, 62, 36.

Swan, K. (2002). Building learning communities in online courses: The importance of interaction. Education, Communication \& Information, 2(1), 23-49.

Triandis, H. C. (1989). The self and social behavior in differing cultural contexts. Psychological review, 96(3), 506

Tu, C. H. (2001). How Chinese perceive social presence: An examination of interaction in online learning environment. Educational media international, $38(1), 45-60$.

Vivilaki, V., \& Johnson, M. (2008). Research philosophy and Socrates rediscovering the birth of phenomenology. Nurse researcher, 16(1), 84-93.

Wang, H. (2006). Teaching Asian Students Online: What Matters and Why?. In Society for Information Technology \& Teacher Education International Conference (pp. 645-650). Association for the Advancement of Computing in Education (AACE).

Wang, P., \& Wang, W. (2012). Causes of and Remedies for Chinglish in Chinese College Students' Writings. Open Journal of Modern Linguistics, 2(02), 71

Wang, M. (2007). Designing online courses that effectively engage learners from diverse cultural backgrounds. British Journal of Educational Technology, 38(2), 294-311.

Wan, G. (1999). The learning experience of Chinese students in American universities: A cross-cultural perspective.

Wong, J. K. K. (2004). Are the Learning Styles of Asian International Students Culturally or Contextually Based?. International Education Journal, 4(4), 154-166.

Wiggins, G. P., \& McTighe, J. (2005). Understanding by design. ASCD.

Xie, S. (2008). Anxieties of modernity: A semiotic analysis of globalization images in China. Semiotica, 2008(170), 153-168 
Yeh, C. J., \& Huang, K. (1996). The collectivistic nature of ethnic identity development among Asian-American college students. Adolescence, 31(123), 645.

Yu, J. (2013). Cultural awareness in Chinese-English translation. Theory and Practice in Language Studies, 3(12), 2322-2326.

Yuan, W. (2011). Academic and cultural experiences of Chinese students at an American university: A qualitative study. Intercultural Communication Studies, 20(1).

Zeng, M. [曾敏]. (2006). The adaptation of Mainland Chinese research postgraduates to the Universities of Hong Kong ( $\mathrm{PhD}$ Dissertation). University of Hong Kong, Pokfulam, Hong Kong SAR. Retrieved November 12, 2018 from http://dx.doi.org/10.5353/th b3700685 